\title{
PERAN SITUS $w w w$.fotografer.net DALAM MEMENUHI KEBUTUHAN INFORMASI BAGI KOMUNITAS FOKUS DI UNIVERSITAS PADJADJARAN
}

\author{
Rhemanus Firdo ${ }^{1}$, Edwin Rizal ${ }^{2}$, Herika Rainathami ${ }^{3}$ \\ ${ }^{1}$ PT Samudera Indonesia, ${ }^{2,3}$ Program Studi Ilmu Perpustakaan Universitas Padjadjaran \\ rhemanus.firdo@yahoo.co.id, ${ }^{2}$ edwin.rizal@unpad.ac.id, ${ }^{3}$ herika.rainathami@unpad.ac.id
}

\begin{abstract}
This research is about how the site of a role in information $w w w$.fotografer.net meet the needs of the user. The purpose of this research is to know the extent to which the intensity of users, content information, and display the website plays a role in meeting the information needs of users. A method of research used is descriptive to describe or expose variables become the object of his research. The technique of adoption the data used in this research comes from two sources of primary data that is obtained via the question form the sampling method of total number of census 54 respondents and secondary data obtained through interviews with the managers of the site www.fotografer.net, observations in the field, as well as the study of librarianship. The results of this research stated that the role of the site www.fotografer.net assess the intensity of the user, the message contents, and appearance are good enough in meeting information needs.
\end{abstract}

Keyword: site, information, information needs

\begin{abstract}
ABSTRAK - Penelitian ini adalah mengenai bagaimana situs www.fotografer.net berperan dalam memenuhi kebutuhan informasi pengguna. Tujuan penelitian ini adalah untuk mengetahui sejauh mana intensitas pengguna, isi informasi, dan tampilan yang terdapat pada website berperan dalam memenuhi kebutuhan informasi pengguna. Metode penelitian yang digunakan adalah deskriptif yang dimaksudkan untuk menggambarkan atau memaparkan variabel- variabel yang menjadi objek penelitiannya. Teknik pengambilan data yang digunakan dalam penelitian ini berasal dari dari dua sumber yaitu data primer yang diperoleh melalui angket metode total sampling/sensus dengan jumlah responden 54 orang, dan data sekunder yang diperoleh melalui wawancara dengan pihak pengelola situs www.fotografer.net, observasi di lapangan, serta studi kepustakaan. Hasil penelitian ini menyatakan bahwa peran situs www.fotografer.net menilai intensitas pengguna, isi pesan, dan tampilan sudah cukup baik dalam memenuhi kebutuhan informasi.
\end{abstract}

Kata kunci: Situs, Informasi, Kebutuhan informasi

\section{PENDAHULUAN}

Perkembangan teknologi dewasa ini berlangsung sedemikian pesatnya para ahli menyebutkan gejala ini sebagai suatu perubahan revolusi yang kelak terjadi yang disebabkan oleh berbagai macam kemampuan dan potensi komunikasi tersebut, sehingga memungkinkan manusia untuk saling berhubungan dan memenuhi kebutuhan akan informasi. Dahulu berbagai keterbatasan dialami manusia dalam berhubungan satu sama lainnya dan sulitnya mendapatkan informasi yang aktual, seperti faktor jarak, waktu dan ruang.

Situs ini pertama kali diluncurkan pada tanggal 30 Desember 2002 oleh Valens Riyadi dan Kristupa Saragih. Situs ini menyediakan galeri secara gratis untuk para fotografer memasang foto-foto karyanya. Di situs ini juga terdapat banyak tutorial tentang fotografi, ruang berdiskusi tentang fotografi dan ruang chat untuk komunikasi bagi sesama fotografer. Di dalam situs ini kita bisa memasang hasil foto-foto kita, mengkritik sekaligus dikritik. Anggota bisa memperoleh rating dengan memasang foto lalu deberi kritikan dengan orang lain atau kita mengkritik foto orang lain. Guna kita kritik dan saran agar menambah pengetahuan, jika ada kekurangan kita dapat memberikan saran atau kritik agar fotografer tersebut mengetahui bagaimana hasil foto-foto yang dia pasang di website tersebut. Tidak dengan 
menaruh foto, mengkritik atau memberi saran, kita juga bisa menaruh artikel agar bisa di baca oleh pengguna-pengguna lainya yang membuka link tersebut. Disinilah esensi dunia fotografi yang kental akan semangat kebersamaan dan saling bantu-membantu dalam arti positif yang di pupuk secara bersama-sama. Tujuan utama situs Fotografer.net adalah memberi kesempatan kepada fotografer untuk memajang hasil karyanya dievaluasi dan dikomentari oleh fotografer lain. (Kristupa 2011). Yang dibidani oleh Kristupa Saragih dan teman-tamanya orang jogya maka jadilah Fotografer.net web fotografi terbesar di Asia tenggara (Alamijaya 2011).

Fenomena yang dari mengkonsumsi situs fotografer.net yaitu setiap individu mempunyai kebutuhan dalam hidupnya baik kebutuhan sehari-hari maupun kebutuhan akan informasi untuk mengetahui masalah yang ada di sekitarnya dalam dunia fotografi, dimana kebutuhan individu dengan kebutuhan individu lainnya tidak sama. Untuk mencari kebutuhan informasi yang dicari tersebut pengguna secara aktif akan memilih situs tersebut yang mana dapat memenuhi kebutuhan yang mereka butuhkan.

Berdasarkan uraian latar belakang diatas, penulis merasa tertarik melakukan penelitian untuk mengetahui kebutuhan informasi bagi anggota FOKUS Unpad (komunitas fotografer dikalangan Fikom di Universitas Padjadjaran) dalam pengetahuan tentang membuat foto yang baik dan indah setelah mereka membaca informasi dan mendapatkan data-data serta referensi foto yang baik melalui website fotografer.net ini. Adakah peran yang signifikan antara penggunaan situs fotografer.net dengan komunitas FOKUS tersebut.

\section{TINJAUAN PUSTAKA}

Teori Uses and Gratification memberikan sebuah kerangka untuk memahami kapan dan bagaimana konsumen media individu menjadi lebih atau kurang aktif dan konsekuensi dari keterlibatan yang meningkat dan menurun. Teori Uses and Gratification ini (teori Penggunaan dan pemenuhan kebutuhan) teori ini menunjukan bahwa yang menjadi permasalahan utama bukanlah media merubah sikap dan prilaku khalayak, tetapi bagaimana media memenuhi kebutuhan informasi. Teori ini bertujuan unutk menjelaskan pertemuan antara kebutuhan seseorang dengan media, atau lebih khususnya lagi informasi yang terdapat dimedia. Oleh karena itu timbulah proses Uses and Gratification yaitu kegunaan dan pemenuhan kebutuhan informasi (Effendy,1993:289-290)

Banyak asumsi Uses and Gratification secara jelas dinyatakan oleh para pencetus ini (Katz, Blummer, dan Gurrevitcth, 1974). Mereka menyatakan bahawa terdapat 5 asumsi dasar teori Uses and Grafitication:

1. Khayalak aktif dalam penggunaan media berorientasi pada tujuan.

2. Inisiatif dalam menghubungkan keputusan pada pilihan media tertentu terdapat pada anggota khalayak.

3. Media berkompetisi dengan sumber lainnya untuk keputusan kebutuhan.

4. Orang mempunyai cukup kesadaran diri akan penggunaan media mereka, minat dan motif sehingga memberikan sebuah 
gambaran yang akurat mengenai kegunaan tersebut kepada peneliti.

5. Penilaian mengenai isi media hanya dapat dinilai oleh khalayak.

Menurut pencetus teori ini Elihu Katz, Haas, dan Michael Gurevitch, konsep dasar dari teori Uses and Gratification adalah meneliti asal mula kebutuhan sebagai sumber-sumber dan psikologis dari kebutuhan yang melahirkan harapan-harapan dari media massa ataupun sumber-sumber lain yang menyebabkan perbedaan pola terpaan media (atau keterlibatan dalam kegiatan lain), dan menghasilkan kebutuhan-kebutuhan lain, bahkan seringkali akibat-akibat yang tidak dikehendaki (Rakhmat, 2007:65).

Setiap orang membutuhkan informasi sebagai bagian dari tuntutan kehidupannya, penunjang kegiatannya, dan pemenuhan kebutuhannya. Rasa ingin tahu seseorang timbul karena ia ingin selalu berusaha menambah pengetahuannya. Krech, Crutchfield, dan Ballachey (Yusup, 1995: 8) lebih jauh menjelaskan karena adanya kebutuhan untuk memecahkan masalah-masalah sosial, seseorang termotivasi untuk mencari pengetahuan, bagaimana caranya agar dapat memecahkan masalah tersebut. Salah satu cara adalah mencari tambahan pengetahuan melalui membaca berbagai media bahan bacaan yang sebagian besar tersedia di perpustakaan.

Fungsi informasi bisa berkembang sesuai dengan bidang garapan yang disentuhnya. Namun setidaknya yang utama adalah sebagai data dan fakta yang membuktikan adanya suatu kebenaran, sebagai penjelas hal-hal yang sebelumnya meragukan, sebagai prediksi untuk peristiwa-peristiwa yang mungkin akan terjadi pada masa yang akan datang. Nyatanya, informasi itu banyak fungsinya. Tidak terbatas pada salah satu bidang atau aspek saja, melainkan menyeluruh, hanya bobot dan manfaatnya yang berbeda karena disesuaikan dengan kondisi yang membutuhkannya (Yusup, 1995: 13).

Taylor (Arsland dalam Rosita, 2006: 29) menjelaskan empat tingkat kebutuhan informasi yaitu: visceral, yaitu informasi aktual yang dibutuhkan tetapi tidak dapat diungkapkan; conscious, merupakan kebutuhan-kebutuhan yang dapat dijelaskan atau digambarkan; formalized, pernyataan resmi atas suatu kebutuhan; dan compromised, yaitu pertanyaan yang diajukan pada sistem informasi.

Dengan kemajuan teknologi di bidang komunikasi dan informasi pada saat ini tidak ada lagi yang di batasi oleh jarak maupun waktu, yang membatasi antar individu untuk berkomunikasi dan memperoleh atau bertukar informasi. Saat ini ruang dan waktu bukanlah hambatan kita untuk berkomunikasi serta untuk memperoleh informasi yang kita butuhkan. Kegiatan untuk berkomunikasi serta memperoleh informasi secara bebas tanpa ada batasan ruang waktu dan batasan lainnya. Ini merupakan filosofis kemunculan internet sebagai teknologi komunikasi dan informasi (Mahayana, 1999: 16-17). Tak bisa dipungkiri dengan hadirnya internet membawa dampak yang sangat besar dalam perkembagan manusia. Internet mempercepat penyebaran dan pertukaran ilmu dan gagasan di kalangan ilmuwan dan cendikawan di seluruh penjuru dunia (Zaleski, 1999:110). 
Dengan akses komunikasi yang begitu cepat dan kemudahan transfer data dan informasi, teknologi komunikasi dan informasi menjadi pendorong globalisasi (Mahayana, 1999:55-54). Revolusi ini telah melahirkan komunikasi dan informasi yang memudahkan kita untuk memperoleh informasi dari segala bidang.

Karakteristik teknologi komunikasi dan informasi diantaranya:

1. Adanya kesempatan dan kebebasan memilih diantara berbagai metode dan untuk melayani kebutuhan manusia dalam komunikasi.

2. Kemungkinan mengkombinasi teknologi metode dan sistem yang berbeda dan terpisah selama ini (konvergensi).

3. Kecenderungan kearah desentralisasi, individualisasi, dalam konsep dan pola pemakaian teknologi komunikasi (Mahayana, Dahlan 1999:12).

Menurut (Suyanto, 2009:61) dalam bukunya Step by Step Web Design menerangkan kriteria situs web yang baik adalah:

1. Usability (Kegunaan)

Usability adalah sebagai suatu pengalaman pengguna dalam berinterkasi dengan aplikasi atau situs website sampai pengguna dapat mengoperasikan dengan mudah dan cepat. Dengan demikian situs website harus memenuhi lima syarat-syarat tingkat usability yang baik :

a) Mudah untuk dipelajari.

b) Efisien dalam penggunaan.

c) Mudah untuk diingat.

d) Tingkat kesalahan rendah.

e) Kepuasan pengguna.

\section{Sistem Navigasi ( Struktur)}

Navigasi membantu pengunjung untuk menemukan jalan yang mudah ketika pengunjung menjelajahi situs website, memberitahu dimana mereka berada, kemana mereka bisa pergi. Dengan demikian mereka dapat menemukan apa yang mereka cari dengan cepat dan mudah.

\section{Graphic Design (Desain Visual)}

Kepuasan visual seorang user secara subyektif melibatkan bagaimana desainer visual situs website tersebut membawa mata user menikmati dan menjelajahi situs website dengan melalui layout, warna, bentuk, dan tipografi. Grafik membuat halaman website menjadi indah tetapi bisa juga memperlambat akses dengan semakin besarnya ukuran file.

\section{Content (Isi)}

Sebaik apapun itu situs website secara desain grafis, tanpa konten yang berguna dan bermanfaat maka akan kurang berarti. Konten yang baik akan menarik, relevan, dan pantas untuk target audien situs website tersebut. Gaya penulisan dan bahasa yang di pergunakan harus sesuai dengan website dan target audiens. Hindari kesalahan dalam penulisan, termasuk tata bahasa dan tanda baca, di tiap halaman, header, dan judulnya. Buat daftar penjelasan untuk istilah-istilah khusus. Konten harus relevan dengan tujuan situs. Situs website sebaiknya memiliki arsip dari konten dan data-data lama. Untuk objektivitas dan ketepatan 
informasi yang terdapat pada konten, lebih baik bila konten itu merupakan hasil kompilasi data yang diperkuat dengan pendapat pihak-pihak yang berwenangan.

5. Compatibility (Kesesuaian)

Situs website harus sesuai dengan berbagai perangkat tampilannya (browser) harus memberikan alternatif bagi browser yang tidak dapat melihat situsnya.

6. Loading Time (Waktu)

Menurut Jeffrey Veen dari webmonkey.com : Kita hanya memiliki 3 detik untuk meyakinkan user untuk tidak menutup window atau pergi ke situs lain, jadi letakan sesuatu di layar dalam waktu 3 detik dan buatlah sesuatu itu menarik. Aturan ini diperlukan oleh webreview, yaitu dengan 8 detik, jika situs web itu mempunyai sebuah image bukan fotografi atau artwork (dalam artian sebenarnya) yang besarnya $40 \mathrm{~kb}$ (satu image). Sebuah penelitian yang dilakukan oleh Zona Resech (April 1999) menyatakan bahwa $80 \%$ pengunjung akan menutup browser bila halaman website yang dibuka tidak tampil dalam 7-8 detik. Penelitian Jupiter Media Matrix (September 2001-Amerika Serikat) mengatakan bahwa $40 \%$ pengunjung situs yang tampil lebih cepat.

7. Functionaly (Fungsi) Seberapa baik sebuah situs website bekerja dari aspek teknologinya, ini bisa melibatkan programer dengan script-nya,

misal HTML (DHTML), PHP, ASP, Coldfusion, CGI, SSI.
8. Accesibility (Aksebilitas)

Halaman website harus bisa dipakai oleh setiap orang, baik anak-anak, orang tua dan orang muda, termasuk orang-orang cacat, Ada berbagai hambatan yang ditemui dari sisi pengguna untuk bisa menikmati halaman website itu. Desainer setidaknya harus mempertimbangkan masalah ini dan memberikan solusinya, terutama yang berhubungan dengan tugasnya sebagai desainer. Untuk hambatan fisik, bagaimana memaksimalkan penggunaan konten ketika satu atau lebih indera dimatikan atau dikurangi kerjanya, terutama untuk user dengan kekurangan indra penglihatan. Pengguna yang mempunyai keterbatasan penglihatan, bisa orang yang memiliki penglihatan kurang jelas, buta warna, sampai yang buta secara total.

\section{Interactivity (Interaktif)}

Buat situs website yang memungkinkan pengunjung berinteraksi dengan situs website, kita sebagai pemilik/pembuat, pengunjung lain, dan dengan komputernya. Interaktivitas adalah apa yang melibatkan pengguna situs website sebagai user exsperience dengan situs website itu sendiri. Dasar dari interaktivitas adalah hyperlink (link) dan mekanisme feedback. Gunakan hyperlink untuk membawa pengunjung ke sumber berita, topik lebih lanjut, topik terkait, atau lainya. Seperti link yang berbunyi More info about this, Glossary, Related Links. 
Sesuai dengan penjelasan di atas peneliti hanya akan memakai tiga kriteria yaitu Contens (isi), Graphic Design (tampilan), karena hal tersebut sangat berkaitan dengan penelitian tentang peran situs www.fotografer.net terhadap pemenuhan kebutuhan informasi bagi komunitas Fokus di Universitas Padjadjaran.

\section{METODE PENELITIAN}

Penelitian deskriptif bertujuan untuk mencari data seluas mungkin dalam rangka mempelajari kondisi sosial dari suatu kelompok manusia, hubungan interaksi antar manusia, dan pola kelakuan manusa. Metode ini dipakai karena penelitian yang akan saya teliti bertujuan untuk mengetahui peran situs $w w w$.fotografer.net dalam memenuhi kebutuhan informasi bagi komunitas Fokus Unpad.

\section{HASIL DAN PEMBAHASAN}

Berdasarkan penelitian yang dilakukan penulis membahas mengenai uraian dan analisis data-data yang diperoleh dari data primer dan sekunder penelitian. Data primer penelitian ini adalah hasil kuesioner yang disebarkan kepada 54 responden. Data tersebut merupakan data pokok dimana analisisnya ditunjang oleh data-data sekunder yang analisisnya didapat dari hasil observasi di lapangan dan beberapa sumber pustaka untuk memperkuat dan memperdalam hasil analisis. Data yang diperoleh dari hasil kuesioner terdiri dari dua macam, yaitu data responden dan data penelitian.

Data responden adalah seluruh identitas responden yang dipandang relevan dengan permasalahan yang diidentifikasi. Sedangkan data penelitian adalah sejumlah skor yang diperoleh dari jawaban responden atas pertanyaan atau pernyataan mengenai variabel penelitian, yaitu variabel $\mathrm{X}$ (Peranan Website situs www.fotografer.net) dan variabel Y (Kebutuhan Informasi Pengguna). Variabel tersebut dianalisis dengan menggunakan statistik deskriptif.

Data-data responden yang diperoleh melalui kuisioner dianalisis secara deskriptif. Data lain yang diperoleh dari studi pustaka akan digunakan sebagai data sekunder untuk melengkapi dan mendukung data primer. (1) Hasil data penelitian, "Antara intensitas penggunaan situs fotografer.net terhadap pemenuhan kebutuhan informasi bagi anggota Fokus Unpad", mengindikasikan bahwa sebagian besar dari responden menilai intensitas pengguna situs fotografer.net terhadap pemenuhan kebutuhan informasi bagi anggota Fokus Unpad kategori tinggi, (2) Hasil data penelitian "Antara Isi Pesan situs fotografer.net terhadap pemenuhan kebutuhan informasi bagi anggota Fokus Unpad", mengindikasikan bahwa sebagian besar dari responden menilai intensitas pengguna situs fotografer.net terhadap pemenuhan kebutuhan informasi bagi anggota Fokus Unpad kategori tinggi, (3) Hasil data penelitian "Antara tampilan situs fotografer.net terhadap pemenuhan kebutuhan informasi bagi anggota Fokus Unpad", mengindikasikan bahwa sebagian besar dari responden menilai intensitas pengguna situs fotografer.net terhadap pemenuhan kebutuhan informasi bagi anggota Fokus Unpad kategori tinggi.

\section{SIMPULAN}

Berdasarkan hasil dari penelitian yang telah dibahas pada Bab IV mengenai Peran Situs www.fotografer.net dalam Memenuhi Kebutuhan 
Informasi bagi Komunitas Fokus di Universitas Padjadjaran, maka dapat disimpulkan sebagai berikut:

1. Berdasarkan intensitas penggunaan media dalam pemenuhan kebutuhan informasi fotografi terletak pada kategori baik. Hal ini menjelaskan bahwa intensitas penggunaan memberikan pengetahuan dan informasi yang dapat dimengerti dan menambah pengetahuan bagi komunitas Fokus tentang pemenuhan kebutuhan mengenai fotografi. Dengan semakin lamanya mengakses media atau sering membuka situs ini, pengunjung mendapatkan informasi yang lebih baik lagi dan terpenuhi kebutuhan informasinya.

2. Berdasarkan isi pesan yang dikonsumsi dalam pemenuhan kebutuhan informasi fotografi terletak pada kategori tinggi. Dimana anggota fokus dalam menggunakan Situs www.fotografer.net dapat dilihat dari isi media dirasa bisa memenuhi informasi tentang fotografi yang sesuai dengan kebutuhan informasi pengguna, sehingga pengunjung mendapatkan informasi yang lebih baik lagi dalam pemenuhan kebutuhan informasi yang di inginkan.

3. Berdasarkan tampilan situs dalam pemenuhan kebutuhan informasi pada fotografi terletak pada kategori tinggi. Dimana anggota fokus dalam menggunakan situs www.fotografer.net dapat melihat dari tampilan situs. Dilihat dari tampilan situs dirasa bisa memenuhi informasi tentang fotografi yang sesuai dengan kebutuhan informasi pengguna, sehingga pengunjung mendapatkan informasi yang lebih baik lagi dalam pemenuhan kebutuhan informasi yang diinginkan.

\section{DAFTAR PUSTAKA}

Alamijaya, Januar. (2011). Web fotografi terbesar di Asia Tenggara: Suatu pengantar. Diakses dari http://kaltim.tribunnews.com/2011/06/20/f otografernet- terbesar-di- asia-tenggara. Diakses pada tanggal 20 juni 2012.

Effendy, Onong Uchjana. (1993). Dinamika Komunikasi, Bandung: Remaja RosdaKarya.

Katz, Blummer dan Gurevitch. (1974). The uses of mass communication. London: Sage Publication.

Mahayana, Dahlan. (1999). Menjemput Masa Depan. Bandung: Remadja Rosda Karya.

Rakhmat, J. (2007). Metode penelitian komunikasi. Bandung: PT. Remaja Rosdakarya

Rostina, Lefie. (2006). Perilaku Pencarian Informasi Tenaga Kesehatan: Studi KAsus

Tentang Perilaku Penemuan Informasi

Tenaga Kesehatan pada Perpustakaan Rumah Sakit Pertamina (RSPP). Tidak diterbitkan.

Saragih, Kristupa. (2011). Seputar Fotografi: Suatu pengantar. Diakses dari http://Fotografer.Net. diakses pada tanggal 15 september 2012

Suyanto, Asep Herman. (2009). Step By Step Design Theory and Practices. Yogyakarta: CV Andi Offset.

Yusup, Pawit M. (1995). Ilmu Informasi, Komunikasi, dan Kepustakaan. Jakarta: Kencana Media Group.

Zaleski, J. (1999). Spiritualitas Cyberspace,trj. Bandung: Mizan. 
